\title{
An Analysis of the Contact Types of Study Abroad Students: The Peer Cohort, the Host Culture and the Electronic Presence of the Home Culture in Relation to Readiness and Outcomes
}

\section{Victor Savicki}

Western Oregon University

In international education the conventional wisdom, supported by research, is that more contact with a host culture yields better results for study abroad students (Dwyer, 2004). Such exposure to a foreign culture is seen as the raison d'etre for study abroad: the mechanism provoking students to challenge their ethnocentric notions and move toward a more inclusive worldview (Engle \& Engle, 2002; Savicki, 2008). However, the relationship between contact and outcomes is a bit more complicated. Some shorter-term programs seem be able to attain outcomes similar to or identical with longer-term programs (Dwyer, 2004). There may be different outcomes depending on both quantity and quality of contact (Voci \& Hewstone, 2003). Many factors may account for this more nuanced connection between foreign culture exposure and positive outcomes, not the least of which are parallel, concurrent contacts with other home culture study abroad students, and continued contact with significant people in the student's home culture. Although contact has been defined as "actual faceto-face interaction between members of clearly defined groups" (Pettigrew \& Tropp, 2006, p. 754), in the age of technology, it may be that electronic contact can have effects as well. The current research attempts to explore the relationships between various types of cultural contact (host culture, American student peers, and home culture) and important aspects of the students' study abroad experience. It will relate these various aspects of contact to precursors of, and readiness for, study abroad, to several outcomes of study abroad, and to psychological processes employed by students during their sojourn. The aim is to shed light on the impact of various forms of contact, and to suggest possible processes underlying differential contact. These underlying processes have implications for education abroad program design. 


\section{The Contact Hypothesis}

Much of the theoretical basis for the idea that contact between people of different cultures can lead to a decrease in ethnocentrism stems from work by Gordon Allport (1954). A major meta-analysis of 50 years of research on Allport's theory does indicate "small to medium" significant reduction of prejudice over a broad variety of intergroup contact situations ( $r$ 's $=-.205$ to -.214 ) (Pettigrew $\&$ Tropp, 2006, p. 757). Said in a different way, this type of contact accounts for between $4 \%$ to $5 \%$ of prejudice reduction. More importantly, when key theoretical conditions are met (equal group status, common goals, intergroup cooperation, and support from authorities), prejudice reduction can be more substantial (a bit more than $8 \%$ of variance accounted for). This is a modest, yet consistent relationship. On the other hand, when conditions of anxiety or threat exist, prejudice and avoidance can actually increase significantly in relation to contact with out-groups (Plant, 2004; Stephan \& Stephan, 1985; Voci \& Hewstone, 2006). The results of contact with a different culture may possibly be beneficial, but may not always be benign.

As Janet Bennett indicates in one of her five foundation principles of developing intercultural competence, "cultural contact does not always lead to a significant reduction of stereotypes" (Bennett, 2008, p. 17). Just placing students in another culture to fend for themselves does not guarantee positive outcomes. Proximity is a necessary but not sufficient condition for social contact (Pettigrew \& Tropp, 2006). Cultural exposure is not "magic;" there is no "alchemy somehow activated by the sheer fact of being abroad” (Engle \& Engle, 2002, p. 26). Particularly important is the recognition that it is difficult to arrange the conditions that Allport (1954) says lead to reduction of prejudice; while at the same time study abroad students are likely to experience stress and anxiety as a result of their clashes with their host culture's "foreignness" (Ward, Bochner, \& Furnham, 2001). Programs must be designed to take into account both exposure to a study abroad culture, and the reflection and processing of cultural clashes in values, assumptions, and expectations. They must provide both challenge and support (Deardorff, Paige, \& Vande Berg, 2008).

Study abroad programs and the advisors who send students to them tout the idea of "cultural immersion." Immersion, as an expression of exposure to a foreign culture, is difficult to quantify. Engle and Engle (2003) have developed a scheme which rates the degree of immersion of study abroad programs based on various characteristics such as duration, language requirements, student housing arrangements, guided reflection on cultural experience, to name a few criteria. This scheme accounts for the study abroad program's features which may both challenge and support students. It also identifies various aspects that may lead to quality of contact, which Stephan, Diaz-Loving, and Duran (2000) say can be more important 
than quantity of contact. Again, the presumption is that programs that fall on the higher end of these continua represent a greater degree of exposure, and therefore have a greater probability of producing positive study abroad outcomes.

Interestingly, the contact hypothesis with regard to the interface between home and host cultures overlooks two important factors that may further complicate this interplay. First, there is some evidence that a "third culture" emerges while students study abroad based on student association with other students from their home culture (Citron, 2002). For simplicity's sake in this paper the students who comprise this third culture, those other students from the home culture, will be referred to as the "peer cohort." Additionally, representatives of the students' home culture may have stronger influence than in the past because of the electronic connections of e-mail and other distance-erasing technologies (Holzmüller, Stöttinger, \& Wittkop, 2002). We take up these issues next.

\section{Peer Cohort Contact}

Commonly, groups of study abroad students assemble in their host culture to partake of the study abroad program, be it as direct enrollment students in a foreign university, or part of a group of students moving together through an academic or service learning experience (Engle \& Engle, 2002; Pusch \& Merrill, 2008). When faced with a foreign culture, it is natural for students from a similar culture, or at least dissimilar from the host culture, to find common cause in their differentness from the host culture (Frey \& Tropp, 2006). This may be especially true when the host culture is somewhat opaque, distant, and difficult to enter. Banding together, students can support each other emotionally and with practical advice and shared experiences. To some extent, such banding together can increase their well-being while exposed to the trials and tribulations of acculturative stress (Savicki, Cooley, \& Donnelly, 2008).

Conversely, such an alliance may pose an impediment to richer and fuller contact with members of the host culture, producing a "ghetto" effect sealing the students off from the host culture (Holzmüller, Stöttinger, \& Wittkop, 2002, p. 140). Citron (2002) suggests that another outcome of such mutual engagement is the emergence of a third culture that is not quite the home culture and not quite the host culture, but some mixture. Evanoff (2006) promotes the idea that cultures can form connections with each other via the construction of a third culture. Such third cultures have the characteristics of "dynamic inbetweenness" (Yoshikawa, 1987) or "hybridity" (Werbner \& Modood, 1997). Engle and Engle (2002), however, see such a development in American study abroad students as a phenomenon of the "hermetic American self" (p. 31) which serves to close off 
students from a more complete immersion in the host culture. Evidence from contact theory research and conceptualizations also supports the idea that stronger out-group stereotyping can be associated with overly limited in-group focus (Frey \& Tropp, 2006; Plant, 2004; Voci \& Hewstone, 2003). Citron's (2002) long-term follow up with study abroad students raises concerns that conformity to the norms of the third culture forecloses options and opportunities for deeper participation in and understanding of the host culture.

Although student reliance on one another in a study abroad setting may be predictable and natural, it can carry both potentially positive and negative effects with regard to desired study abroad outcomes.

\section{Electronic Presence of the Home Culture}

Electronic communication today is pervasive. Current study abroad students from the U.S. have come to rely on a number of means of contact via the Internet (e-mail, voice over Internet protocol (VOIP), instant messaging) as well as voice phone and text messaging. Many study abroad sites have instituted options for Internet and mobile phone access for their students. On the one hand, such access allows students to keep in contact with each other, and to maintain psychological support from important people back home. On the other hand, it may impose problems for study abroad goals. Holzmüller, Stöttinger, and Wittkop (2002) state that "As Internet and email facilitate quick and inexpensive communication with home, students may have less inclination to make the necessary investments to cope with the host culture" (p. 139).

Beyond the concerns about interference with face to face host culture contact, electronic communication may also impose an undue influence of home culture representatives on the acculturation process of study abroad students. Rather than gaining some distance from American values, students may have those values indiscriminately reinforced by significant others back home who are not aware of the immediate cultural context of the students, nor are flexible or creative in their views of what tasks the students may be facing. Research studies have not yet evaluated the impact of electronic communication of study abroad students (Holzmüller, Stöttinger, \& Wittkop, 2002). The current study hopes to shed some light on this issue.

In summary, cultural contact may be expressed in many ways. Certainly, the expected interface between a student's home culture and their study abroad culture will be influenced by the amount of time and effort they exert in dealing with the affective, behavioral, and cognitive aspects of acculturation (Ward, 2001). Concerns about the proportion of home and host culture influence and 
engagement loom large in international education. However, much of what the field believes about this cross-cultural contact lacks adequate research support. Add to this mix the third culture of American student peer cohort, as well as the home culture influence of electronic communication, and there remains much to discover about how these various types of cultural contacts and influences mesh or grind in the study abroad process.

The current study is exploratory. The data will help to clarify some of the expectations and assumptions expressed in the preceding sections.

\section{Methods}

\section{Participants}

Students. Study abroad student participants were 59 U.S. university students studying abroad in four different countries (Austria $=16$, Greece $=9$, Italy $=11$, Spain $=23$ ). Average age was 21.5 years; $65 \%$ were women; $42 \%$ were seniors, $52 \%$ were juniors, $6 \%$ were sophomores. They sojourned in their respective countries for approximately three months during the Fall.

Study abroad sites. With regard to characteristics of immersion in the host culture, the study abroad sites varied along a somewhat uneven continuum. At the lower immersion end, Program 1 offered academic courses in English on the program site. Students shared apartments with other American students in the same program. Language courses were required, but virtually no student had any prior spoken fluency, nor had they taken formal classes in the language. The local language courses were offered on site to program participants only. Offering a bit more immersion, Program 2 conducted academic courses in English on the program site. Students lived with home stay families in the local community. Roughly $40 \%$ of students had some fluency in the local language prior to arrival and had taken formal coursework in the local language. Language courses were offered on site to program participants only and were differentiated on the basis of ability. Program 3's academic courses were offered in English on the program site, with some class activities offered in the local language. Students lived in apartments with other American students and students from other cultures. Some students arrived with language fluency and formal coursework, and all students took differentiated language classes at the local university in classes with students from many different cultures. At the higher end of the immersion continuum, Program 4 offered academic courses in the local language at the program site with American program participants. Language fluency was required for entry into the program, and all students had taken formal courses in the language. Students lived with home stay families in the local community. Language courses were offered 
at differentiated levels at the local university with students from several cultures. Beyond these differences, all sites had several characteristics in common. They all had one U.S. faculty, as well as several host culture faculty who taught a variety of academic courses. All sites taught a required intercultural communication class throughout the student sojourn. All sites provided opportunities for cultural interaction, experiential learning, and guided reflection on student cultural experience (cf. Arrúe, 2008; Binder, 2008; Minucci, 2008). Using Engle and Engle's categories of cross-cultural contact, the programs spanned Level Three: Crosscultural Contact Program, and Level Four: Cross-cultural Encounter Program with some features from Level Five: Cross-cultural Immersion Program (Engle \& Engle, 2003). Later immersion analysis will be based on these groupings.

\section{Measures}

General Contact levels. Percent of contact with individuals from different cultures was measured by student responses to the following question:

When thinking about the last month, please estimate the percent of time you spent in face to face contact with the following kinds of people (the percentages should add to 100\%). In situations in which you may encounter more than one type of person at once (e.g. host culture teacher in a class with fellow American students), please count that as contact with the host culture.

The response alternatives were 1. American students, 2. People in the host culture (teachers, shop keepers, other students, etc), and 3. People of a different culture (neither home nor host culture).

Specific contact levels. Several specific contact options for both host culture and home culture were assessed using a six-point Likert scale from $0=$ Never to 5 = Daily. Cross-culture contact options include items such as "Interact with other culture people in your accommodations (home stay or apartment)," "Interact with other culture people in daily situations (shop keepers, bartenders, taxi drivers, etc.)." Home culture contact options focused on the range of options for contacting people in the U.S. such as "Letter/postcards via the postal system," "e-mail," "Instant messaging." With regard to home culture contact, students were also asked to report the total number of minutes per week spent in contact activities with home culture people.

Satisfaction with Life Scale (SWLS). The SWLS is a five item questionnaire using a seven point Likert scale to rate overall satisfaction with life using questions such as "In most ways my life is close to my ideal" (Diener, Emmons, 
Larsen, \& Griffin, 1985). The SWLS can be viewed as a measure of psychological adjustment since the scale demonstrated moderately strong criterion validity with several measures of psychological well-being (Diener, Emmons, Larsen, \& Griffin, 1985 pp. 72-73). Alpha for the current sample was 853.

Brief Symptom Inventory (BSI). Psychological strain was measured based on four sub-scales from the BSI (Derogatis \& Melisaratos, 1983). The five-six item symptom cluster scales included were Somatization: distress arising from perceptions of bodily dysfunction; Depression: dysphoria and lack of motivation and energy; Anxiety: nervousness, panic attacks, apprehension, dread; and Hostility: thoughts, feelings or actions of anger. Coefficient alphas for the sub-scales were Somatization .780, Depression .827, Anxiety .746, Hostility .744.

Positive and Negative Affectivity Schedule (PANAS). Positive and negative mood were assessed with the PANAS; (Watson, Clark, \& Tellegen, 1988). The Positive Activation subscale lists 10 adjectives related to positive mood (e.g. active, alert, attentive). The Negative Activation subscale lists 10 adjectives related to negative mood (e.g. afraid, ashamed, distressed). Participants were asked to rate the extent to which they had felt each of these emotions over the previous three months. Ratings were made on a five-point Likert scale, ranging from $1=$ Very slightly or not at all to $5=$ Extremely. Alphas for the current sample were Positive Activation, .832; Negative Activation, .858.

Acculturation Index (AI). Ward and Rana-Deuba (1999), using Berry's (1997) acculturation concept, developed the 21-item AI that compares how much respondents identify with their culture of origin in comparison with the culture they are visiting or living in. Each item is rated on a 7-point Likert scale ranging from $1=$ Not at all similar to $7=$ Extremely similar for both the home and host cultures. Subsequent analysis develops scores for Home Culture Identification and Host Culture Identification, which can then be compared to determine the category of acculturation expressed by each respondent: Marginalized, Integrated, Assimilated, Separated. Alpha for Home Culture Identification was .912 and for Host Culture Identification was .854 .

Socio-cultural Adaptation Scale (SCAS). In the SCAS Ward and Kennedy (1999) have identified a list of encounters, and issues that may be relevant to sociocultural adjustment. Respondents rate their adjusting to cultural situations using a five-point Likert scale with $1=$ No difficulty to $5=$ Extreme difficulty. A brief sample of their 29-item scale includes "Making friends," "Using the transport system," "Going shopping," "Understanding the locals' world view" (Ward \& Kennedy, 1999 p. 663). Reliability based on Cronbach's alpha for the current sample was .858. In addition, Ward and Kennedy (1999) factor analyzed their 
scale and found two factors: Cultural Empathy and Relatedness (13 items, 32\% of variance), and Impersonal Endeavors and Perils (7 items, 9\% of variance).

Intercultural Adjustment Potential Scale (ICAPS). The ICAPS consists of 55 items with responses given on a scale ranging from $1=$ Strongly Disagree to $7=$ Strongly Agree. A total score (ICAPS Total) was computed by summing all items (24 reverse coded) with higher scores indicating greater adjustment potential (Matsumoto, et al., 2001). This scale has demonstrated predictive validity for adjustment to a new culture based on peer and expert interviewer ratings, as well as self and subjective ratings (Matsumoto, et al., 2001 p 492). Four factor scores were also derived: 1) Emotion Regulation (ER): the ability to modulate one's emotional reactions to avoid employing psychological defenses, 2) Openness (OP): the ability to engage in learning about the new culture, 3) Flexibility (FL): being free of over-attachment to previous ways of thinking and willingness to tolerate ambiguity, and 4) Critical Thinking (CT): the ability to generate creative, new hypotheses about incidents in the new culture that go beyond one's home cultural framework. All five ICAPS scores were transformed to T-scores with a mean of 50 and standard deviation of 10 based on a normative sample. The authors of the scale reported alphas of .783 for the ICAPS Total, .638 for Emotional Regulation.601 for Openness, .568 for Flexibility, .433 for Critical Thinking (Matsumoto, et al., 2001).

Big Five Personality Inventory (Big 5). Personality was measured using a short version of the Big 5 personality factor approach (Fossum, Weyant \& Etter, Feldman-Barrett, 1996). For this 35-item scale, each sub-scale had 7 items. The scales and key defining traits for each include: 1) Neuroticism: anxious, hostile, self-conscious; 2) Extraversion: outgoing, sociable, upbeat, assertive; 3) Openness to experience: curiosity, flexibility, unconventional attitudes; 4) Agreeableness: sympathetic, trusting, cooperative, straightforward; 5) Conscientiousness: diligent, disciplined, well-organized, dependable. Alphas for the sub-scales in this sample are Neuroticism .768, Extraversion .773, Openness . 731, Agreeableness .611, Conscientiousness . 707.

Ego-Resiliency Scale (ERS). The ERS assesses the trait of psychological resilience, which is the capacity to respond effectively to changing situational demands, especially frustrating or stressful encounters (Block \& Kremen, 1996). This scale consists of 14 items, each responded to on a 4-point Likert scale, ranging from $1=$ does not apply at all to $4=$ applies very strongly. Sample items include "I quickly get over and recover from being startled," and "I enjoy dealing with new and unusual situations." For the current sample, the alpha reliability was .744. 
Coping Inventory (COPE). The COPE (Carver, Scheier, \& Weintraub, 1989) is a 60 -item, theory-based scale with fifteen 4 -item subscales. Alphas reported are for the current sample.

1. Active coping is the process of taking active steps to try to remove or circumvent the stressor or to ameliorate its effects. Examples include initiating direct action, increasing ones efforts, and trying to execute a coping attempt in a stepwise fashion $(\alpha=.557)$.

2. Planning is thinking about how to cope with a stressor. Planning involves coming up with action strategies, thinking about what steps to take and how to best handle the problem $(\alpha=.785)$.

3. Suppression of competing activities means putting other projects aside, trying to avoid becoming too distracted by other events, even letting other things slide, if necessary, in order to deal with the stressor $(\alpha=.628)$.

4. Positive reinterpretation and growth is construing a stressful transaction in positive terms with the result of helping the person continue or resume problem-focused coping $(\alpha=.683)$.

5. Restraint coping is waiting until an appropriate opportunity to act presents itself, holding oneself back, and not acting prematurely $(\alpha=.735)$.

6. Instrumental social support is seeking advise, assistance, or information $(\alpha=.804)$.

7. Emotional social support is getting moral support, sympathy, or understanding $(\alpha=.887)$.

8. Religion is seeking comfort, consolation, and/or guidance from a higher power. This might be either within the framework of an organized religion or more informally through attention to the spiritual side of life $(\alpha=.956)$.

9. Humor is seeing the absurdities and potentially funny side of a stressful event. It may include jokes, sarcasm, irony, wit, and other ways of reevaluating the event through use of humor $(\alpha=.892)$.

10. Focus on venting emotions is the tendency to focus on whatever distress or upset one is experiencing and to ventilate, or express, those feelings $(\alpha=.817)$.

11. Denial is refusing to believe that the stressor exists or trying to act as if the stressor is not real $(\alpha=.744)$. 
12. Mental disengagement is distracting oneself from thinking about the stressor. Tactics may include using alternative activities to take one's mind off the problem $(\alpha=.526)$.

13. Behavioral disengagement is reducing one's effort to deal with the stressor, even giving up the attempt to attain the goals with which the stressor is interfering $(\alpha=.701)$.

14. Acceptance is accepting that the stressor cannot be changed and getting on with accommodating to the situation as it is $(\alpha=.737)$.

15. Alcoholand drugs means using chemicals to blunt the feelings associated with exposure to the stressor $(\alpha=.995)$.

Prior exposure to other cultures. Several questions concerning student's prior exposure to other cultural influences were asked, e.g. number of weeks of previous foreign travel, years of foreign language study, number of friends from other cultures.

\section{Procedures}

Students responded to measures voluntarily with assurance of confidentiality. Prior exposure information, the Big 5, the ERS, the COPE and the ICAPS were completed prior to departure for the study abroad placement. The Contact measures, SWLS, BSI, SCAS, AI, and PANAS measures were all taken at the end of the student study abroad sojourn.

\section{Results and Discussion}

Results will be presented first with regard to general and specific contact types, with reference to concepts of immersion and cultural distance. Following will be an analysis of precursors to contact levels, relationships of contact to study abroad outcomes, and the relationship of concomitant process variables to contact.

\section{General contact}

The means for three types of general contact were significantly different. On average the study abroad students spent the largest percentage of their time in contact with their Peer Cohort ( $M=58.95 \%, S D=19.16)$, followed by contact with Host Culture people $(\mathrm{M}=31.44 \%, \mathrm{SD}=16.46)$, and with people of Other Cultures (neither home nor host culture) $(M=10.71 \%, S D=9.70)$. Figure 1 shows how this contact was distributed over ten percentage groupings. There is wide variation in the amount of contact, especially in the home and host culture percentages. On average, the study abroad students in this study spent almost 
Figure 1. Percentages of Types of General Cultural Contact

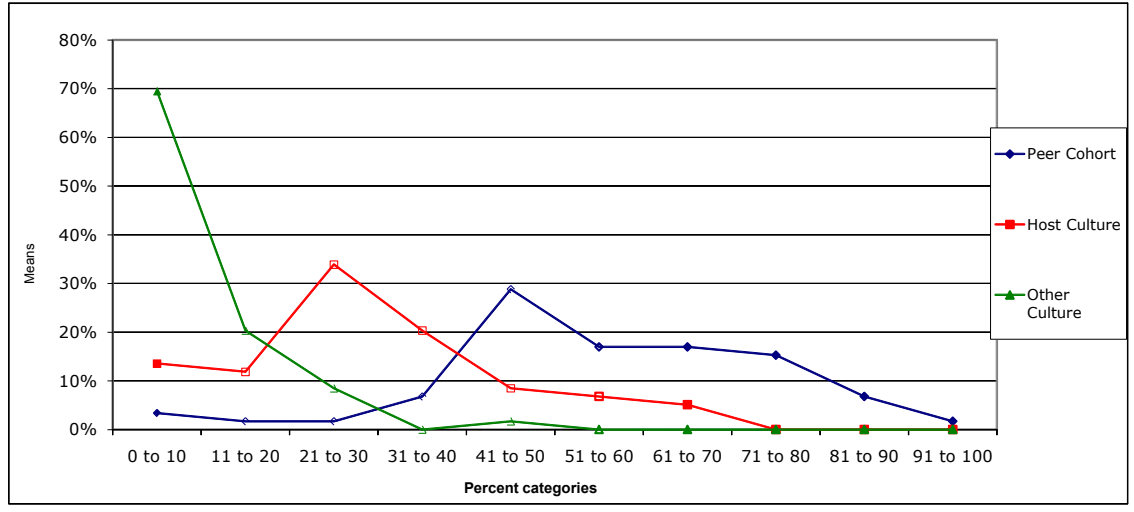

twice as much time with each other as they did with people in the host culture (Wilcoxon signed ranks $=-5.126, p<.001$ ).

Although the means for types of contact with the Peer Cohort and Host Culture people from the four immersion categories described earlier (Programs 1-4) were in the anticipated directions (i.e. more immersion related to lower Peer Cohort contact and higher Host Culture contact), the immersion groups were not significantly different on any of the general measures of contact $(F=1.445, p<\mathrm{ns})$. There appeared to be enough variation in individual student response within each immersion group to offset the mean differences. Neither was the cultural distance (Kogut \& Singh, 2001) between the U.S. and the host culture related to any of the three general contact types ( $r$ 's $=.130,-.084$, and -.176 respectively).

Although there were significant differences between contact types, neither the immersion level of the program nor the characteristics of the culture seemed to relate to these differences.

\section{Specific contact}

Beyond a gross measure of general contact types, more specific measures of contact indicated a variety of responses to both the foreign culture, and the students' home culture.

Host culture contact. Table 1 shows that contact with people from the study abroad and other cultures was high (Often to Very often) within the student's living accommodations (home stay, apartment), in daily situations in the host culture community (shopkeepers, etc.), and through speaking the host culture language outside of their formal language classes. Contact with the study abroad and other cultures was lower (Seldom to Sometimes) with language conversation 


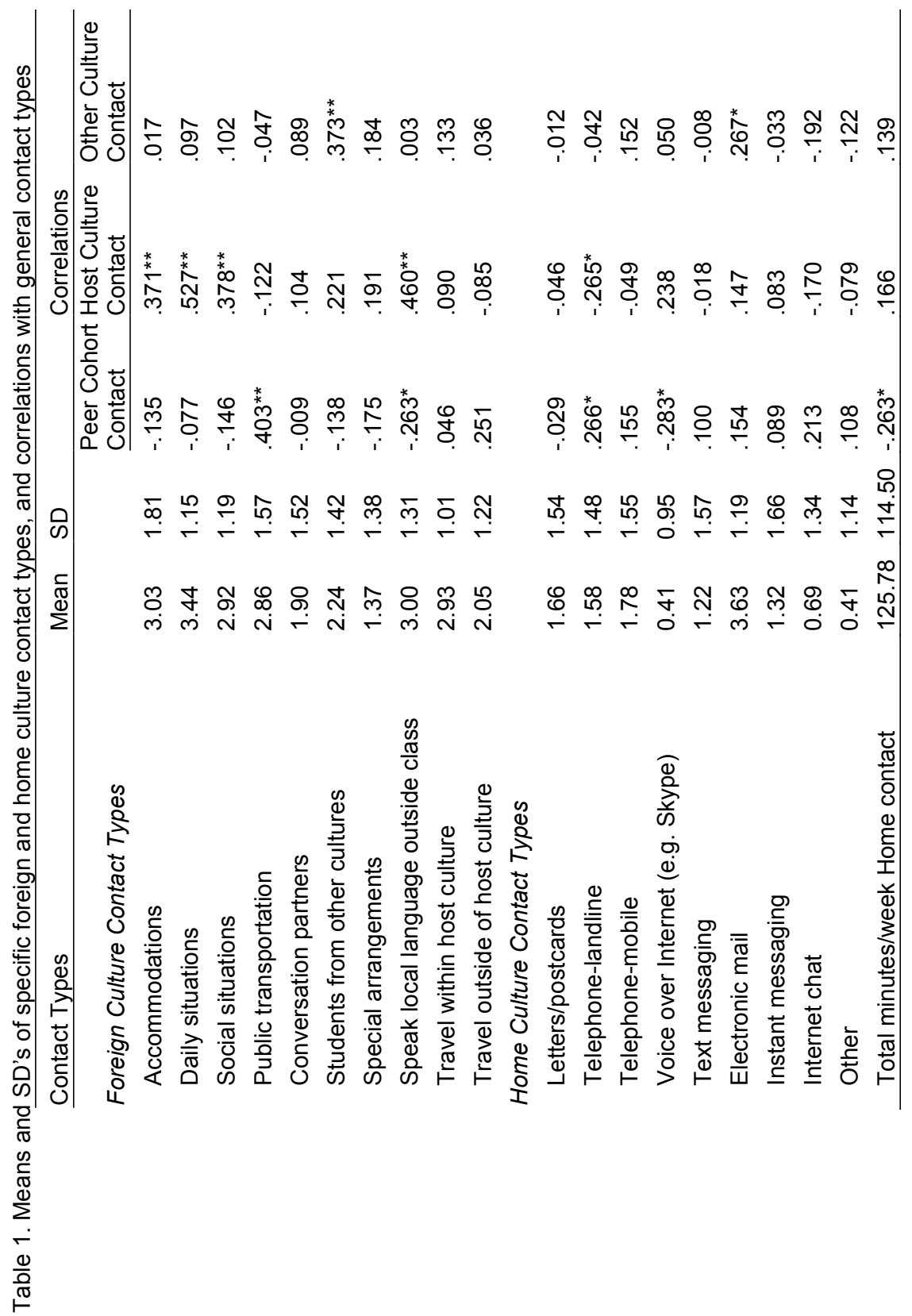


partners and for specially-arranged activities (e.g. music lessons). Clearly there is a range of frequency between different foreign culture contact types.

Correlations of general Host Culture contact with specific contact types show that students who spent more time with host culture people did so in their living situations, in daily interactions with shopkeepers, and others, and in social situations such as clubs, coffee houses, and social events. Host Culture contact was significantly related to speaking the local language outside of formal language classes (see table 1). Other Culture contact was related significantly to interacting with students from other cultures rather than to travel. Peer Cohort contact was positively related to using public transportation and inversely related to speaking the local language outside of classes. The pattern of correlation of specific contact types to general contact types indicates the differential emphasis of activities underlying the more general types of contact with foreign culture.

Home culture contact. Table 1 shows that contact with people from students' home culture was accomplished by a number of methods, the most preferred being electronic mail (Often to Very often). The traditional postal service and telephone (voice and text messaging) followed in frequency (Seldom to Sometimes) followed by Voice of Internet and Internet chat. On average students spent approximately two hours per week in activities contacting people in their home culture.

Correlations show that students with higher general Peer Cohort contact more frequently used a landline telephone, and less frequently used Voice over Internet. They also contacted people back home less often (see table 1). Students with higher Host Culture contact used landline phones less often to contact home. Even though electronic mail was the preferred mode of communication back home, neither Peer Cohort contact nor Host Culture contact were related to email use; whereas, Other Culture contact was positively related. The amount of time spent in contact with the Home culture was unrelated to Host Culture contact but inversely related to Peer Cohort contact.

In summary, individual variations of general contact types were related to specific contact activities with both foreign culture and home culture. Home Culture contact did not seem to interfere with Host Culture contact.

\section{Precursors to general contact differentiation}

Because individual variation in percentage of time spent with the three general contact types seemed to mute the impact of level of immersion or general cultural distance, it might be useful to understand what experiences and student characteristics prior to the study abroad sojourn might be predictive of the manner in which they eventually allotted time to the types of contact. 


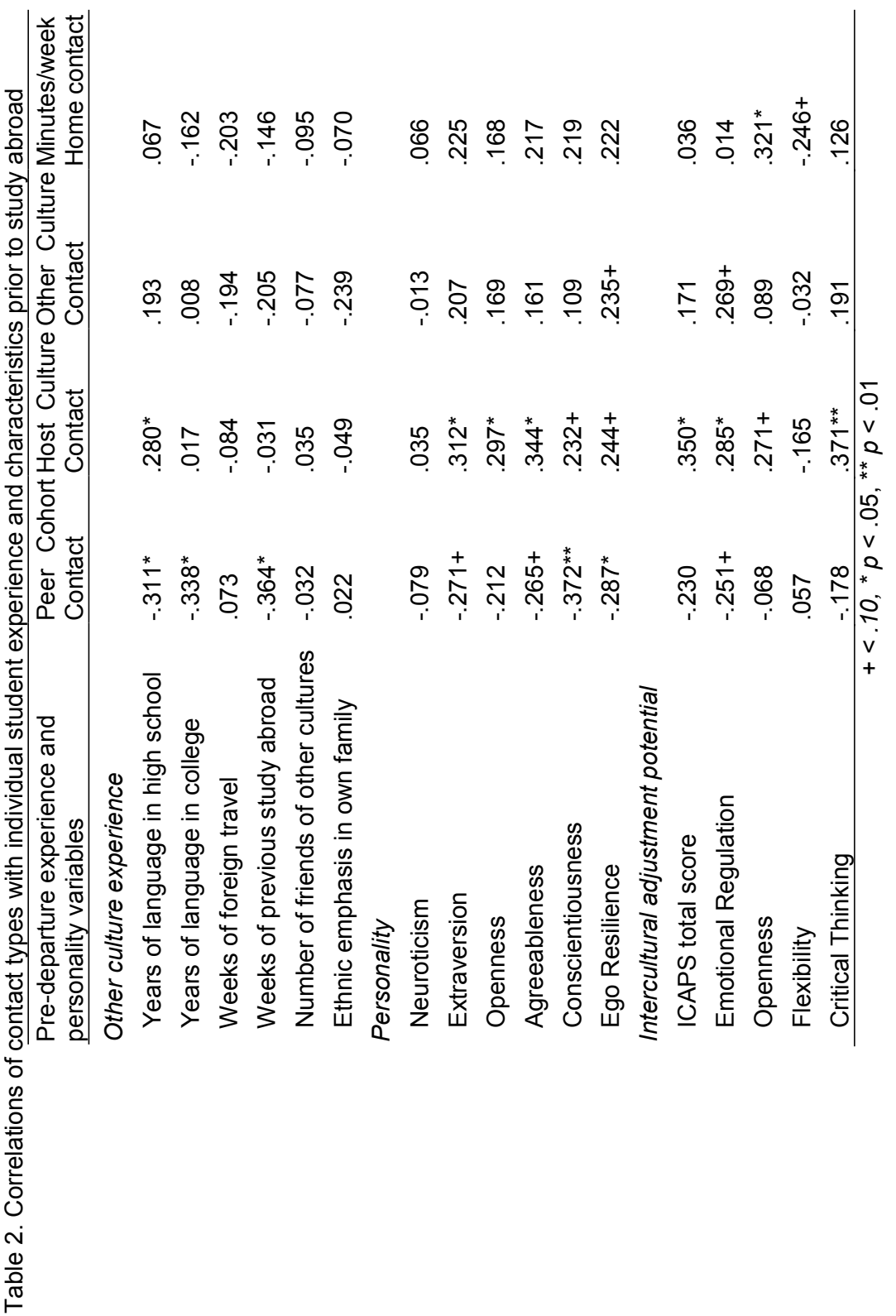


Prior experience with other cultures. Table 2 indicates that students with a higher percentage of Peer Cohort contact also had fewer years of language course work both in high school and at the university. They also had had fewer weeks of previous study abroad experience. Students with a higher percentage of Host Culture contact had more years of high school language. Previous foreign travel, number of friends from other cultures, or emphasis on ethnic origins within the student's family were not related to differences in contact types. Higher percentages of Peer Cohort contact were not so much related to the presence of prior experiences as to their absence.

Predeparture personality characteristics. Table 2 also indicates a reasonably distinct pattern in personality characteristics related to differentiation between contact types. The personality variables of Extraversion, Agreeableness, Conscientiousness, and Ego Resilience were all positively correlated with percent of Host Culture contact and inversely correlated with Peer Cohort contact. Openness was also positively correlated with Host Culture contact. Even though some of these correlations only marginally significant, they point to a profile of personality characteristics that may make it easier to establish, and sustain contact with the host culture. More outgoing, stress tolerant, persistent students who find it easier to get along with others, and who look for new experiences show higher levels of host culture contact. Lower levels of these characteristics may propel students into more familiar, less stressful interactions with fellow American peers in their study abroad program. Such characteristics may also be predictive of anxiety toward out-groups, which has been shown to relate to identification with and preference for in-group interaction (Plant, 2004; Voci \& Hewstone, 2003).

Intercultural adjustment potential. Predeparture measures of potential for intercultural adjustment correlated positively for percent of Host Culture contact: overall intercultural potential (ICAPS Total), Emotional Regulation, and Critical Thinking (see table 2). Students with higher percentages of Host Culture contact were more likely to be able to modulate their emotional responses to acculturative stressors, and were more able to think through cultural difficulties in a creative fashion. These relationships were absent for student with higher percentages of Peer Cohort contact.

In summary, aspects of prior experience, of personality characteristics, and of measured potential for intercultural adjustment, all assessed prior to student departure for their study abroad, were significantly related to percentages of contact with both the Peer Cohort and with Host Culture individuals during the student sojourn. In general, students with higher percentages of host culture contact showed higher readiness for study abroad on a number of different levels. 


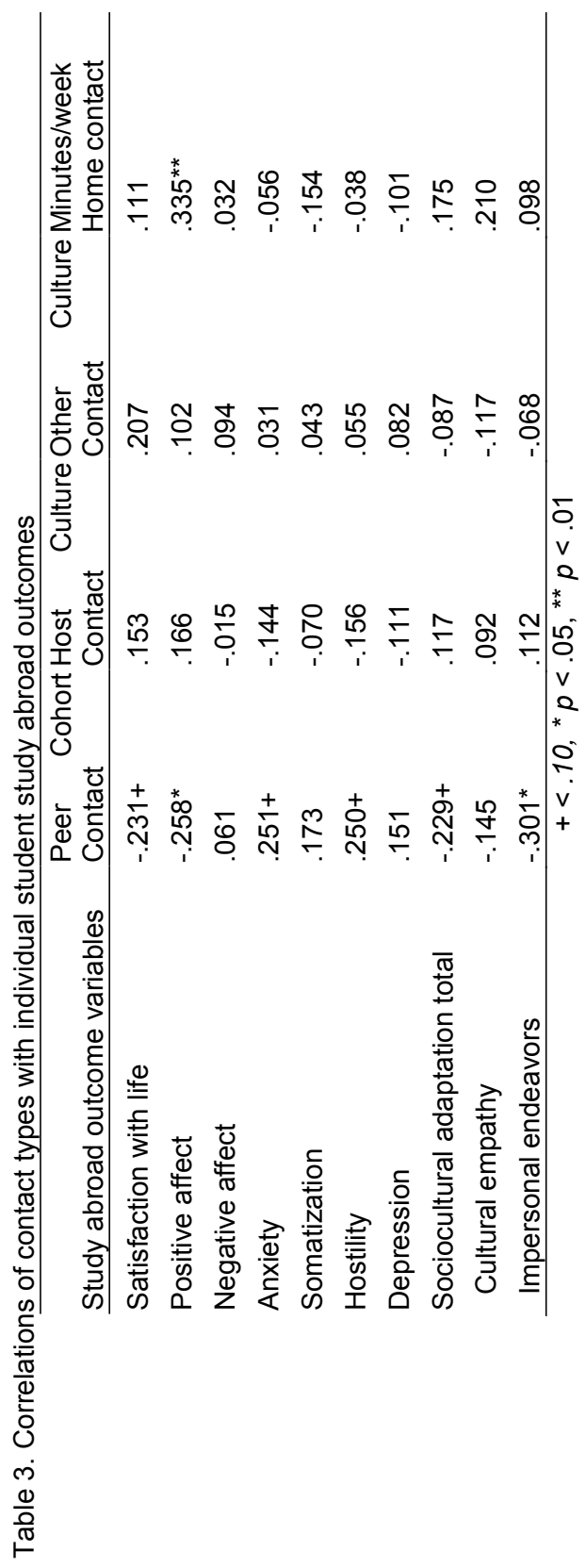




\section{Study abroad outcomes related to general contact differentiation}

Following Ward (2001) we will discuss a sampling of study abroad outcomes using the $\mathrm{ABC}$ model which categorizes variables as Affect, Behavior, and Cognition.

Affect and Behavior. Table 3 shows the relationship of various affective and behavioral study abroad outcome measures with general contact types. Home Culture contact was significantly related to Positive Affect. Interestingly, the study abroad outcomes showed no significant relationships with Host Culture contact. Higher percentages of contact with the Host Culture were not associated with better outcomes either at the affective level (satisfaction, affect, psychological symptoms) or at the behavioral level (sociocultural adjustment) (Ward, 2001). However, a pattern of relationships (some only marginally significant) did emerge for contact with the Peer Cohort. Higher percentages of Peer Cohort contact were related to lower outcome measures of Satisfaction with Life, Positive Affect, and Sociocultural Adaptation. At the behavioral level, students who showed higher Peer Cohort contact also continued to have difficulty with the activities in the Impersonal Endeavors and Perils sociocultural factor: the day-to-day encounters with the foreign culture such as finding food you enjoy, dealing with unsatisfactory service. In addition, marginally significant correlations with psychological symptom scales of Anxiety and Hostility may indicate a psychological state of mild agitation for students with higher percentages of Peer Cohort contact. Such affective responses have been shown to mediate lower out-group contact (Plant, 2004; Voci \& Hewstone, 2003). Higher Peer Cohort contact was associated with lower study abroad outcomes. Correlation is not causation; therefore, we cannot say that one caused the other, or if both were caused by another influence. Therefore, we also need to examine precursors as well as concomitant processes that may influence these results.

Cognition. Berry $(1997,2005)$ used a categorization of social identification at the cognitive level to describe strategies of acculturation. Based on methodology suggested by Ward and Rana-Deuba (1999), students in the current study were assigned to one of four acculturation strategy groups based on their degree of identification with their home and host cultures. Figure 2 shows the significant differences of acculturation strategies on general contact types $(F=4.843$, $p<.001)$. Students who adopted the Separation strategy (26\% of the sample), of high identification with home culture and low identification with host culture, showed both a significantly higher percentage of Peer Cohort contact $(F=5.256, p<.001)$, and a significantly lower percentage of Host Culture contact 


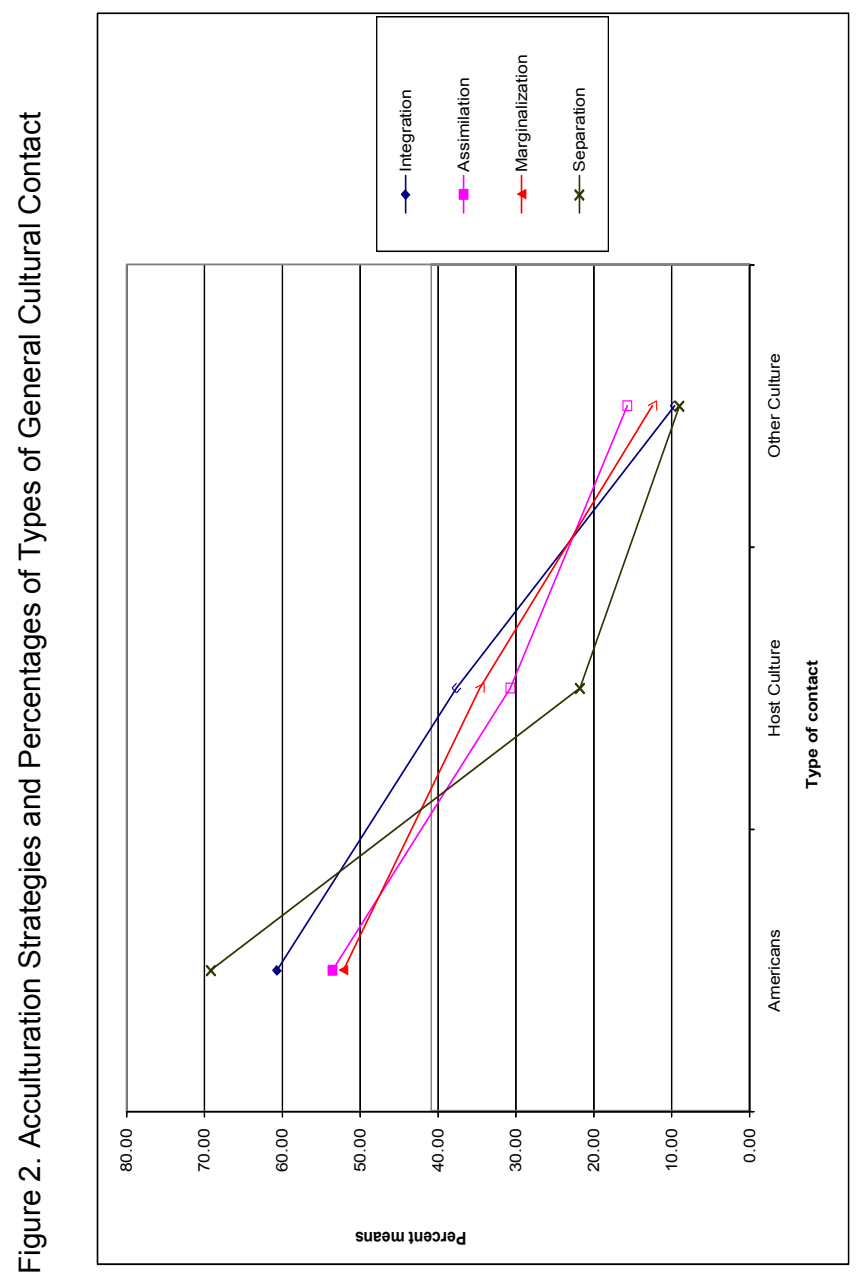

$(F=3.690, p<.01)$. These students were, indeed, maintaining separation between themselves and the host culture by means of high levels of contact with fellow American student peers. Although none of the other acculturation strategy groups were significantly different from each other, a Duncan's Range post hoc analysis showed that the Separation group overlapped with the Integration group on percent of Peer cohort contact $(p<.05)$. Students who adopted the Integration strategy (38\%), with both high home and host culture identification, showed both high levels of contact with both the Host Culture and with Peer Cohorts. Contact with other American student peers did not seem to interfere with their contact with host culture people. Students using either 
the Marginalization (24\%) or the Assimilation (12\%) strategies showed lower Peer Cohort contact and fell between the Separation and Integration strategy students on Host Culture contact. From Berry's point of view (2005) the Integration strategy is preferred since it allows students to draw upon resources from both home and host cultures during their acculturation process. The Separation strategy, in contrast, provides fewer such options.

In summary, differentiation of general contact types shows significant relationships to a number of outcomes of study abroad. In general, higher Peer Cohort contact was related to lower measures of outcomes. Higher Host Culture contact showed mixed results.

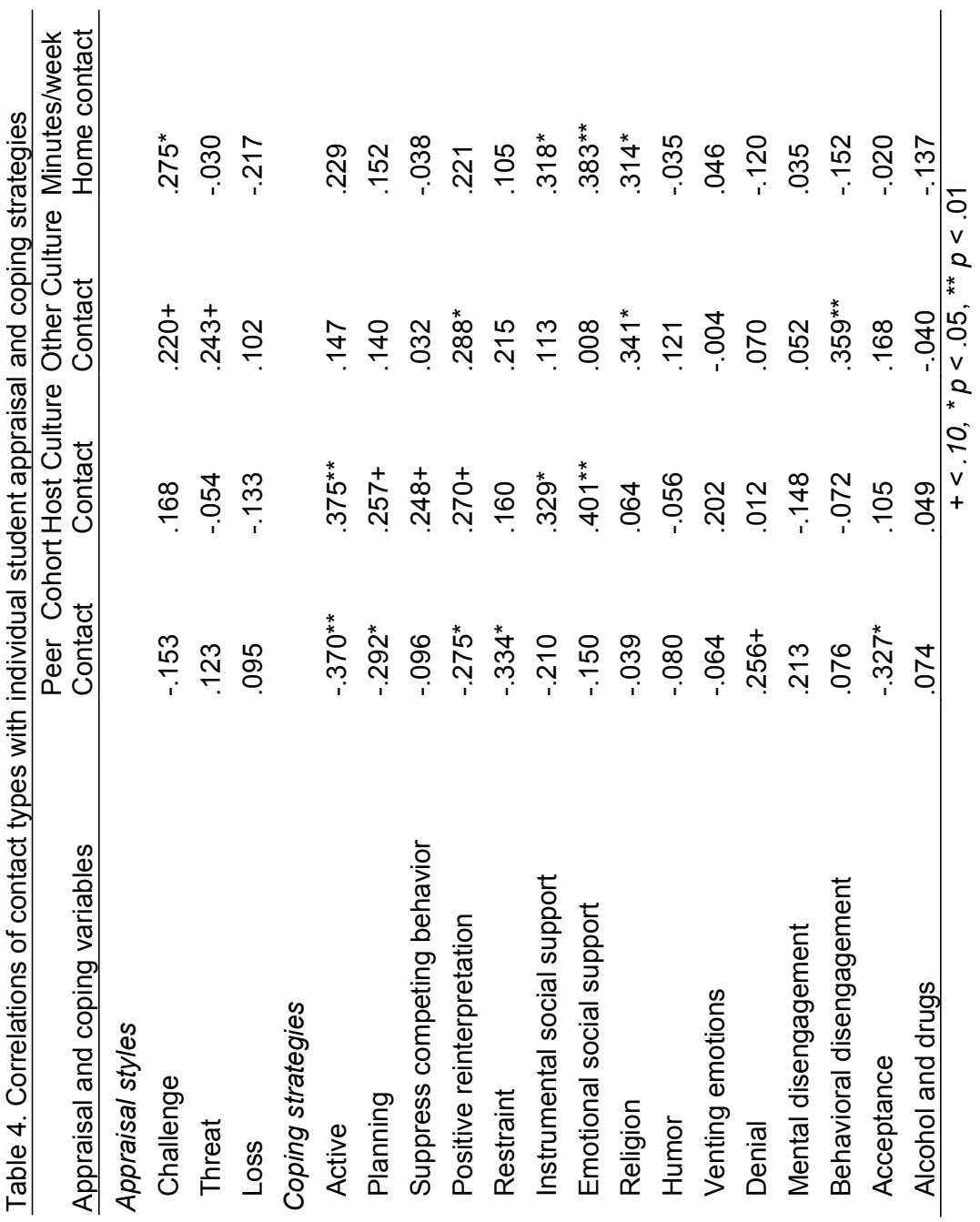




\section{Concomitant psychological processes related to general contact differentiation}

Student reports of appraisal styles and coping strategies showed several patterns relating those psychological processes to general contact differentiation (see Table 4). The significant correlation between the appraisal style of Challenge with the minutes per week of contact with people in the U.S. may indicate that this contact by computer, phone, or letters may have been an important resource for students to deal with acculturative stress as it arose. The significant correlations of Home contact with both the Instrumental and Emotional Social Support coping strategies as well as Religion coping further fleshes out the likely purpose of student connection with U.S. resource people. Appraisal styles were not related to percentage of contact with the Peer Cohort nor Host Culture, and only marginally related to Other Culture contact.

An interesting pattern of coping strategies (some only marginally significant) appeared between the students with higher Peer Cohort contact and those with higher Host Culture contact. Correlations in opposing directions for Active coping, Planning, and Positive Reinterpretation indicate that students with higher Host Culture contact showed higher functional coping (Carver, Scheier, \& Weintraub, 1989) while students with higher Peer Cohort contact showed lower functional coping. That is, past research has shown these coping strategies to be associated with higher psychological well-being during study abroad (Savicki, Downing-Burnette, Heller, Binder, \& Suntinger, 2004). Additionally, higher Host Culture contact was also related to greater use of both Instrumental and Emotional Social Support and of Suppressing Competing Activities. Students with higher Host Culture contact were able to draw on a variety of functional coping strategies. Two further coping strategies related to Peer Cohort contact were also revealing. Such contact was related to lower levels of Acceptance and higher levels of Denial. That is, students with higher percentages of contact with other American student peers in their program were more likely to pretend that problems did not exist, or were not difficult, and they were less likely to acknowledge and accommodate to the situation as it was. It seemed that the choice of coping strategies for students with higher contact with American student peers may have perpetuated distressing conditions rather than remediating or relieving them.

In summary, both appraisal and coping approaches were related to general contact differentiation, and they revealed patterns that may help to explain both student preferences for the types of contact they made during their study abroad, as well as some of the outcomes they attained. 


\section{Conclusions}

Students who engaged in a higher percentage of Host Culture contact seemed to show a higher degree of readiness for study abroad, as well as a more functional set of psychological strengths to cope with the acculturative stresses they encountered. Although personality characteristics are not easily amenable to change, there are several teachable skills and abilities employed by students with higher Host Culture contact that international educators may find helpful for future study abroad students. For example, training in critical thinking, positive reinterpretation, emotional regulation, and planning my be incorporated into orientation and on site courses to help students think about, reassess, and an react differently to cultural clashes. The talents and abilities of successful students may be sharable; thus providing guidance in program design. Of note, however, is that percentage of Host Culture contact was not related to affective and behavioral outcomes of study abroad as measured in this study. The modest overall relationship of contact to prejudice reduction seems to imply that other factors, such as anxiety and negative expectations of intercultural contact may also play a part (Voci \& Hewstone, 2003). Apparently, it is not host culture contact alone that leads to positive outcomes. Unfortunately, the "magic" is not there.

The finding that percentage of Peer Cohort contact was related to a number of problematic outcomes and psychological processes is discouraging, yet not totally unexpected. Some students are not well prepared to meet the challenges of study abroad. However, embedded in the Peer Cohort contact percentages may be an important distinction. Students using the Separation acculturation strategy (Berry, 2005) and those using the Integration strategy were not statistically different in terms of Peer Cohort contact, yet they seem to have constructed an entirely different study abroad experience. The key seems to be the balance of Peer Cohort and Host Culture contact. Contact with other American students, in and of itself, may not be problematic. However, such contact paired with lower Host Culture contact may be indicative of a number of negative study abroad affective and behavioral outcomes, as well as ineffective coping strategies. From a social psychological perspective, it may be more functional to rearrange the study abroad environment than to blame students for retreating into a "safe" enclave of American in-group (Plant, 2004). Required host culture contact paired with adequate encouragement, coaching, and reflection may provide an effective balance of challenge and support. Anxiety about contact with host culture people may not be the barrier (Voci, 2006), rather negative expectations may be the key deterrent (Plant, 2004). The continued difficulty of students to deal with everyday encounters with the host culture indicates that 
some of these negative expectations did not diminish over time. The data seem to indicate that it is not what the higher Peer Cohort contact students do that is the problem, but rather what they lack and what they avoid doing. Such a situation is easier to remediate.

Another potentially helpful strategy would be to identify "high risk" students prior to departure, and to develop a way to modulate the challenge vs support balance to meet their needs. There is some concern about "coddling" students by providing too much of what they want and not enough of what they need (Engle \& Engle, 2002). However, there is no "one size fits all" international education design (Selby, 2008). Early identification and intervention are tried and true methods to deal with individuals who may lack the abilities necessary to tackle acculturative stressors on their own. The instruments used in this study may provide hints about how to identify needy students.

Counseling students out of study abroad opportunities on the basis of their lack of readiness does not make sense in terms of the broader goal of international education to extend its benefits to more people. Indeed, the students most likely to benefit from a study abroad experience may be the ones least prepared by previous experience and inclination. As the number of students seeking, and being encouraged to study abroad increases, international educators will have to find ways of dealing with students who would not be "swimmers" in the "sink or swim” approach to study abroad program design (Selby, 2008). Additionally, as international education moves to recognize "softer" measures of study abroad outcomes, such as attitude change and values clarification, the field also needs to consider the ethical problems of programmatic design that may result in more prejudice and ethnocentrism rather than less (Savicki \& Selby, 2008).

Finally, concerns about email and other forms of contact with home culture significant social support seem to be unfounded on the basis of the current study. Contact with the Home Culture via these means did not interfere with Host Culture contact, and it was inversely related to Peer Cohort contact. Furthermore, it was related to appraising the study abroad experience as a challenge rather than as a threat. Student access to home culture support may provide another means helping students to cope with the complexities of acculturative stress.

The contact hypothesis is alive and well in the field of international education. However, it is a bit more nuanced than we often imagine it to be. Many different types of contact may combine to support or hinder the goals we set for our study abroad students. Clearly some students thrive while others succumb to the pressures of acculturative stress. As international educators, we can improve our program design to help attain our goals. Both challenge and support are needed. 


\section{References}

Allport, G. W. (1954). The Nature of Prejudice. Cambridge, MA: Addison-Wesley. Arrúe, C. (2008). The eye of the beholder: Study abroad in Spain viewed through multicultural lenses. In V. Savicki, (Ed). Developing Intercultural Competence and Transformation: Theory, Research, and Application in International Education (pp. 236-258). Sterling, VA: Stylus Publishing.

Bennett, J. M. (2008). On becoming a global soul: A path to engagement on study abroad. In V. Savicki, (Ed). Developing Intercultural Competence and Transformation: Theory, Research, and Application in International Education (pp.13-31). Sterling, VA: Stylus Publishing.

Berry, J. W. (1997). Immigration, acculturation and adaptation. Applied Psychology: A international review, 46.5-34.

Berry, J. W. (2005). Acculturation. In W. Friedlmeier, P. Chakkarath, \& B. Schwarz (Eds.) Culture and Human Development (pp. 291-302). New York, NY: Psychology Press.

Binder, F. (2008). Case studies for integration of experience and understanding while studying in Vienna. In V. Savicki, (Ed). Developing Intercultural Competence and Transformation: Theory, Research, and Application in International Education (pp. 259-275). Sterling, VA: Stylus Publishing.

Block, J. \& Kremen, A. M. (1996). IQ and ego-resiliency: Conceptual and empirical connections and separateness. Journal of Personality and Social Psychology. 70, 349-361.

Carver, C.S., Scheier, M.F., \& Weintraub, J.K. (1989). Assessing coping strategies: A theoretically based approach.Journal of Personality and Social Psychology, $56,267-283$.

Citron, J. L. (2002). U. S. students abroad: Host culture integration or third culture formation. In W. Grünsweig \& N. Rinehart, (Eds.). Rockin' in Red Square: Critical Approaches to International Education in the Age of Cyberculture (pp. 41-56). Münster: LIT Verlag.

Deardorff, D. K., Paige, R. M., \& Vande Berg, M.(2008). Supporting Student Learning Abroad. Presentation at the Forum on Education Abroad. Boston, MA.

Derogatis, L. R. \& Melisaratos, N. (1983). The brief symptom inventory: An introductory report. Psychological Medicine, 13, 595-605.

Diener, E., Emmons, R. A., Larsen, R. J., \& Griffin, S. (1985). The satisfaction with life scale. Journal of Personality Assessment, 49,71-75.

Dwyer, M. M. (2004). More is better: The impact of study abroad duration. Frontiers: The Interdisciplinary Journal of Study Abroad, X, 151-163. 
Engle, J. \& Engle, L. (2002). Neither international nor educative: Study abroad in the time of globalization. In W. Grünsweig \& N. Rinehart, (Eds.). Rockin' in Red Square: Critical Approaches to International Education in the Age of Cyberculture (pp. 25-39). Münster: LIT Verlag.

Engle, L. \& Engle, J. (2003). Study abroad levels: Toward a classification of program types. Frontiers: The Interdisciplinary Journal of Study Abroad, IX, 1-20.

Evanoff, R. (2006). Integration in intercultural ethics. International Journal of Intercultural Relations, 30, 421-437.

Fossum, T.A., Weyant, S.A., Etter, L., Feldman Barrett, L. (1998, May). A short and simple alternative to long personality questionnaires. Presented at the annual meeting of the American Psychological Society, Washington, DC.

Frey, F. E. \& Tropp, L. R. (2006). Being seen as individuals versus as group members: Extending research on metaperception to intergroup contexts. Personality and Social Psychology Review, 10, 265-280.

Holzmüller, H. H. Stöttinger, B. \& Wittkop, T. (2002). Information and communication technologies in internationalized business education: Technical opportunities and interpersonal threats. In W. Grünsweig \& N. Rinehart, (Eds.). Rockin' in Red Square: Critical Approaches to International Education in the Age of Cyberculture (pp. 127-146). Münster: LIT Verlag.

Kogut, B., \& Singh, H. (2001). The effect of national culture on the choice of entry mode. Journal of International Business Studies, 19, 411-432.

Matsumoto, D., LeRoux, J. A., Iwamoto, M., Choi, J. W., Rogers, D., Tatani, H., \& Uchida, H. (2003). The robustness of the Intercultural Adjustment Potential Scale (ICAPS): The search for a universal psychological engine of adjustment. International Journal of Intercultural Relations, 27, 543-56.

Minucci, S. (2008). Italy: Every day another soulful experience to bring back home. In V. Savicki, (Ed). Developing Intercultural Competence and Transformation: Theory, Research, and Application in International Education (pp. 215-235). Sterling, VA: Stylus Publishing.

Pettigrew, R. F. \& Tropp, L. R. (2006). A meta-analytic test of intergroup contact theory. Journal of Personality and Social Psychology, 90, 751-783.

Plant, E. A. (2004). Responses to interracial interactions over time. Personality and Social Psychology Bulletin, 30, 1458-1471.

Pusch, M. D. \& Merrill, M. (2008). Reflection, reciprocity, responsibility and committed relativism. In V. Savicki, (Ed.). Developing Intercultural Competence and Transformation: Theory, Research, and Application in International Education (pp. 297-321). Sterling, VA: Stylus Publishing. 
Savicki, V. (2008). Preface. In V. Savicki, (Ed). Developing Intercultural Competence and Transformation: Theory, Research, and Application in International Education (pp. 259-275). Sterling, VA: Stylus Publishing.

Savicki, V., Cooley, E., \& Donnelly, R. (2008). Acculturative stress, appraisal, coping and intercultural adjustment. In V. Savicki, (Ed.). Developing Intercultural Competence and Transformation: Theory, Research, and Application in International Education (pp. 173-192). Sterling, VA: Stylus Publishing.

Savicki, V., Downing-Burnette, R., Heller, L., Binder, F., \& Suntinger, W. (2004). Contrasts, changes, and correlates in actual and potential intercultural adjustment. International Journal of Intercultural Relations. 28, 311-329.

Savicki, V. \& Selby, R. (2008). Synthesis and conclusions. In V. Savicki, (Ed.). Developing Intercultural Competence and Transformation: Theory, Research, and Application in International Education (pp. 342-352). Sterling, VA: Stylus Publishing.

Selby, R. (2008). Designing transformation in international education. In V. Savicki, (Ed). Developing Intercultural Competence and Transformation: Theory, Research, and Application in International Education (pp. 1-10). Sterling, VA: Stylus Publishing.

Stephan, W. G., Diaz-Loving, R., \& Duran, A. (2000). Integrated threat theory and intercultural attitudes: Mexico and the United States. Journal of Crosscultural Psychology, 31, 240-249.

Stephan, W. G., \& Stephan, C. W. (1985). Intergroup anxiety. Journal of Social Issues, 41, 157-176.

Voci, A. (2006). The link between identification and in-group favouritism: Effects of threat to social identity and trust-related emotions. British Journal of Social Psychology, 45, 265-284.

Voci, A. \& Hewstone, M. (2003). Intergroup contact and prejudice toward immigrants in Italy: The mediational role of anxiety and the moderational role of group salience. Group Processes and Intergroup Relations, 6, 37-54.

Ward, C. (2001). The A, B, Cs of acculturation. In D. Matsumoto(Ed.),Handbook of Culture and Psychology. (pp. 411-446). NY: Oxford University Press.

Ward, C., Bochner, S., \& Furnham, A. (2001). The Psychology of Culture Shock $2^{\text {nd }}$ Ed. London: Routledge.

Ward, C. \& Kennedy, A. (1999). The measurement of sociocultural adaptation. International Journal of Intercultural Relations 23. 659-677.

Ward, C., \& Rana-Deuba, A. (1999). Acculturation and adaptation revisited. Journal of Cross-cultural Psychology, 30, 422-442. 
Watson, D, Clark L.A., Tellegen, A, (1988). Development and validation of brief measures of positive and negative affect: The PANAS scales. Journal of Personality and Social Psychology, 54, 1063-1070.

Werbner, P. \& Modood, T. (Eds.), (1997). Debating culture hybridity. London: Zed Books.

Yoshikawa, M.J.(1987). The double-swing model of intercultural communication between the East and the West. In L. D. Kincaid (Ed.), Communication Theory: Eastern and Western Perspectives (pp. 319-329). San Diego, CA: Academic Press. 